\title{
Cause and Timing of First Allograft Failure in Orthotopic Liver Transplantation: A Study of 177 Consecutive Patients
}

\author{
Jorge Quiroga, ${ }^{1}$ Inmaculada Colina, ${ }^{1}$ A. Jake Demetris, ${ }^{2}$ Thomas E. Starzl ${ }^{3}$ and David H. Van Thiel ${ }^{3}$ \\ ${ }^{2}$ Department of Internal Medicine, Clinica Universitaria de Navarra, Pamplona, Spain 31080, and Departments of \\ ${ }^{2}$ Pathology and ${ }^{3}$ Surgery, University of Pittsburgh School of Medicine, Pittsburgh, Pennsylvania 15261
}

\begin{abstract}
The cause and timing of first liver allograft failure was evaluated in 177 patients who underwent a second liver transplant between January 1984 and December 1988. The population studied consisted of 94 men and 83 women with a mean age $41.3 \pm 1.0 \mathrm{yr}$ (mean \pm S.E.M.). Mean first-graft survival was $130.6 \pm 22.9$ days (range $=0$ to 2,073 days). Sixty-eight percent of the grafts failed in the first postoperative month, 26\% failed between the second and twelfth month and only $6 \%$ failed beyond the twelfth month from the date of the initial transplant. Six principal causes of graft failure were identified. Early allograft losses occurred as a result of four major problems: primary graft nonfunction $(30.0 \%$ of all grafts; mean graft survival $=3.4 \pm 0.3$ days); ischemic injury of the graft without overt vascular injury $(9.6 \%$; mean graft survival $=17.5 \pm 1.9$ days); acute rejection $(10.7 \%$; mean graft survival $=30.4 \pm 6.4$ days); and overt vascular complications $(26.6 \%$; mean graft survival $=59.6 \pm 24.1$ days). Late graft failures were the result of either chronic rejection (11.3\%; mean graft survival $=496.3 \pm 136.0$ days) or recurrence of the primary liver disease $(6.8 \%$; mean graft survival $=550.5 \pm 172.1$ days). Graft failure occurred as a result of a variety of miscellaneous causes in $5 \%$ of the cases (mean graft survival in this group $=300.0 \pm 110.6$ days). Overall 6-mo patient survival after a second liver transplant was $46.3 \%$. Patients who had a retransplant because of chronic rejection and ischemic injury had the greatest $(65 \%)$ and least (23\%) 6-mo survival rates respectively after second grafting $(p<0.05)$. Those who survived the second transplant procedure for 6 mo or more tended to be younger $(p<0.01)$ and had a reduced first transplant requirement for red blood cells $(p<0.05)$, platelets $(p<0.01)$ and fresh frozen plasma $(p<0.01)$ than did those who died during the 6 mo after their second transplant procedure. (HEPATOLOGY 1991;14: 1054-1062.)
\end{abstract}

Orthotopic liver transplantation (OLTx) has profoundly altered the otherwise fatal outcome for patients

Received January 15, 1991; accepted June 19, 1991.

Dr. J. Quiroga and Dr. I. Colina were supported in part by a grant from Clinica Universitaria de Navarra, Pamplona, Spain.

Address reprint requests to: David H. Van Thiel, M.D., 5C Falk Clinic, 3601 Fifth Avenue, Pittsburgh, PA 15213.

$31 / 1 / 32912$ with end-stage liver disease. One-year survival rates after OLTx exceed 70\% at most centers (1-3). Despite improvements in organ procurement, surgical technique, postoperative care and immuosuppression, primary failure of a hepatic allograft remains an important clinical problem (1-3), and primary graft failure often determines the success or failure of a given transplant procedure. This unpredictable complication leads to early retransplantation in $10 \%$ to $20 \%$ of the patients undergoing OLTx (1-8). Available data from several institutions indicate that graft rejection, technical problems and ischemic injury of the allograft account for most of these early graft failures $(1,3,5-7)$. In addition, cases of primary disease recurrence have been reported as a cause of late graft failure $(1,3)$. A complete picture of the causes and timing of initial allograft liver failure and the factors that contribute to such graft failures remain to be established. Knowledge of such issues should lead to a reduction in the frequency of this particular problem and thereby improve the overall prognosis of patients undergoing OLTx. This study was undertaken to determine the causes and the timing of first liver graft failure and retransplantation and to determine the influence of primary graft failure and retransplantation on recipient survival. In addition, the relationships between the cause of initial graft failure and the primary liver disease; age and gender of the recipient; and the operative requirement for blood and blood products at the time of initial OLTx were assessed to determine whether predictions might be possible as to which recipients are at greater or lesser risk of graft failure.

\section{PATIENTS AND METHODS}

The records of 180 adult patients receiving a second OLTx at the University of Pittsburgh between January 1984 and December 1988 were studied. Three of these patients had received their first OLTx at another institution and therefore were excluded from the study. Thus a final total of 177 patients having a failed primary liver graft were studied in detail. The initial OLTx procedure was performed in 1982 in 3 patients, in 1983 in 3 patients, in 1984 in 16 patients, in 1985 in 31 patients, in 1986 in 42 patients, in 1987 in 38 patients and in 1988 in 44 patients. Over this same time interval, a total of 905 transplant procedures were performed at this institution. The specific details for patient selection, the surgical procedure, the postoperative supportive care, the immunosuppressive reg- 
TABLE 1. Characteristics of patients studied

\begin{tabular}{lccc}
\hline $\begin{array}{c}\text { Primary liver } \\
\text { discase }\end{array}$ & Number & $\begin{array}{c}\text { Moan age } \\
(\mathbf{y r})^{6}\end{array}$ & $\begin{array}{c}\text { Gender } \\
(\mathbf{M} / \mathbf{F})^{\mathbf{c}}\end{array}$ \\
\hline 1. ChLD & 54 & $43.4 \pm 1.7$ & $18 / 36$ \\
2. Chronic PLD & 85 & $40.5 \pm 1.3$ & $\mathbf{5 3 / 3 2}$ \\
3. NLD & 16 & $50.9 \pm 2.7^{d}$ & $13 / 3$ \\
4. FHF & 14 & $29.3 \pm 3.9^{\circ}$ & $7 / 7$ \\
5. MISC & 8 & $37.7 \pm 4.4$ & $3 / 5$ \\
TotAL & 177 & $41.3 \pm 1.0$ & $94 / 83$ \\
\hline
\end{tabular}

a See text for specific diseases included in each category.

${ }^{b}$ Mean \pm S.E.M.

${ }^{c} \chi^{2}$ for the distribution $=17.32(p<0.01)$.

${ }^{d} \mathrm{p}<0.01$ vs. $1,2,4$ and 5 .

ep $<0.01$ vs. 1 and 2 .

imens used and the follow-up clinical management of these patients have all been described previously (9-11).

The sample experiencing primary graft failure consisted of 94 men and 83 women ranging in age from 17 to $70 \mathrm{yr}$ $(41.3 \pm 1.0$, mean \pm S.E.M. $)$ The primary liver disease, gender distribution and mean age at the time of the first OLTx for these 177 patients are shown in Table 1. For statistical purposes, the primary liver diseases were distributed into five different categories. Category 1 was chronic cholestatic liver disease (ChLD), which included patients with PBC $(n=33)$, primary sclerosing cholangitis $(n=19)$, Caroli's disease $(n=1)$ and cystic fibrosis $(n=1)$. Category 2 was chronic parenchymal liver disease (PLD), which included patients with HBV-induced cirrhosis $(n=18)$, non $A$, non $B$ (NANB) virus-induced cirrhosis $(n=21)$, autoimmune chronic liver disease $(n=9)$, ethanol-associated cirrhosis $(n=12)$, cryptogenic cirrhosis $(n=15), \alpha_{1}$-antitrypsin deficiency $(n=4)$, hemochromatosis $(n=3)$, Wilson's disease $(n=1)$, thorotrast cirrhosis $(n=1)$ and halothane cirrhosis $(n=1)$. Category 3 was fulminant hepatic failure (FHF) occurring as a result of NANB virus infection in five patients, HBV infection in five patients (one of whom also had a delta virus infection) and uncertain cause in four patients. Category 4 was neoplastic liver disease (NLD), which included hepatocarcinoma $(n=8)$, fibrolamellar carcinoma $(n=3)$, epithelioid hemangioendothelioma $(n=2)$, cholangiolar carcinoma $(n=2)$ and liver metastases from an intestinal carcinoid tumor $(n=1)$. Category 5 was a miscellaneous group (MISC) consisting of patients with the Budd-Chiari syndrome $(n=3)$, polycystic liver disease $(n=2)$ and one each of nodular regenerative hyperplasia, congenital hepatic fibrosis and multiple hepatic adenomatosis.

The intraoperative events occurring at the time of the first OLTx, the pretransplant and posttransplant clinical data including all diagnostic procedures performed between the first and second OLTx, the operative findings at the time of the second OLTx and the pathological findings in the failed liver graft were reviewed for each case.

Although more than one factor often contributed to the failure of a given graft, only one factor was chosen for each patient as the principal factor responsible for the graft failure, with all of the remaining factors considered as contributory findings. This assignment was based on a consensus consisting of at least four of the authors. The causes of graft liver failure were classified in one of the following seven categories: Category 1 was primary graft nonfunction (PNF). This diagnosis was ascribed to grafts that failed to demonstrate

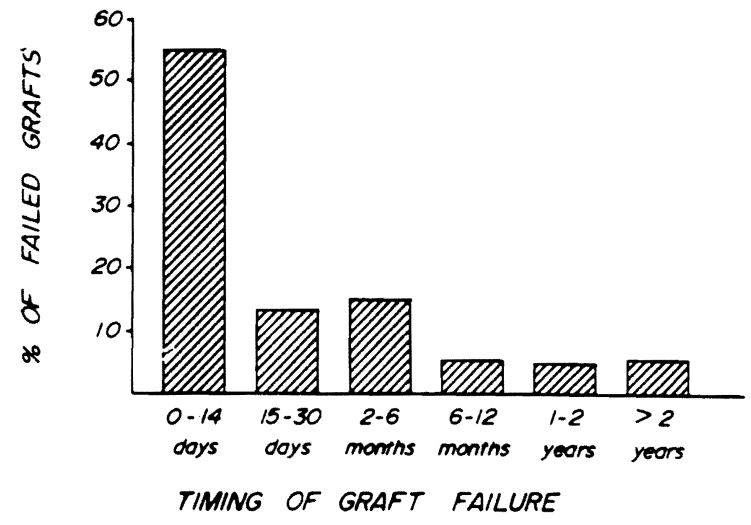

FIG. 1. Timing of graft failure in the 177 patients studied.

function immediately after OLTx and that had pathological evidence of ischemic necrosis and for which no specific technical cause could be identified; Category 2, ischemic graft injury without overt vascular injury (IJ), was ascribed to grafts that initially functioned but eventually failed and that demonstrated pathological findings of ischemic liver injury in the absence of any identifiable thrombotic or nonthrombotic structural abnormality of the hepatic artery (HA), the portal vein, the hepatic veins or the vena cava. Category 3 , a diagnosis of acute rejection (AR), required the presence of histopathological evidence of severe acute rejection in the failed graft using previously well-described histopathological criteria (12). Category 4 was a diagnosis of a vascular complication (VC) that required both the demonstration of an $\mathrm{HA}, \mathrm{PV}$ or hepatic venous thrombosis or vascular anastomotic abnormality, such as a vascular dissection or stricture that may have reduced the blood flow to the liver, and gross and microscopic hepatic pathological conditions characteristic of a vascular injury such as parenchymal necrosis, infarction, abscesses, bile duct necrosis or any combination of these problems (13). Category 5 was chronic rejection (CR), which was diagnosed only in cases where the graft had well established histopathological evidence for severe CR (12). Category 6 was recurrence of the primary liver disease (REC), which was considered to have occurred in grafts that developed identical histopathological lesions as those present in the native liver and for which no other cause for this histopathological appearance could be identified (e.g., patients with $\mathrm{HBV}$-induced primary liver disease, a positive serological result at the time of the diagnosis of recurrence and the demonstration of both $\mathrm{HBsAg}$ and $\mathrm{HBcAg}$ in the allograft liver). Category 7 included cases who did not fit into any of the above six groups; they were culled together as a miscellaneous (MISC) group.

Graft survival was determined as the time interval between the first and second OLT $x$ in days. To evaluate the distribution of individual causes of graft failure across time, six arbitrary time periods were considered. Period 1 was 0 to 14 postoperative days; period 2 was 15 to 30 postoperative days; period 3 was 2 to 6 mo after OLTx; period 4 was 7 to 12 mo after OLTx; period 5 was 13 to 24 mo after OLTx; and period 6 was more than 24 mo after OLTx. Patient survival was updated as of June 1989, with a minimum follow-up of 6 mo after the second OLTx.

The preoperative diagnosis for the first graft failure was defined as the diagnosis found in the preoperative surgical record and was specified immediately before the second transplant procedure. Those matching with the diagnosis 
TABLE 2. Causes of graft failure in cases studied

\begin{tabular}{|c|c|c|c|c|}
\hline $\begin{array}{l}\text { Cauce of } \\
\text { graft failure }\end{array}$ & $\begin{array}{l}\text { Number of } \\
\text { patients }\end{array}$ & $\begin{array}{l}\text { Percent of } \\
\text { patients }\end{array}$ & $\begin{array}{l}\text { Timing of graft } \\
\text { failure (days) }\end{array}$ & Areociated findings in the graft \\
\hline 1. PNF & 53 & 30.0 & $3.4 \pm 0.3^{6}$ & $\begin{array}{l}\text { Moderate AR(2), Cholangitis (1), Herpes (1), Partial IH-HAT (4), } \\
\text { PVT (1) }\end{array}$ \\
\hline 3. $\mathrm{AR}$ & 19 & 10.7 & $30.4 \pm 6.4$ & $\begin{array}{l}\text { Partial IH-HAT (3), HAT (1) , HAT + PVT (1) Cholangitis (1), } \\
\text { CMV (3), E-B (1), Focal BDN (2), Moderate CR (1) }\end{array}$ \\
\hline 6. REC & 12 & 6.8 & $550.5 \pm 172.1^{d}$ & Partial IH-HAT (1), Moderate CR (2) \\
\hline 7. MISC & 9 & 5.0 & $300.0 \pm 110.6$ & See text \\
\hline
\end{tabular}

$\mathrm{IH}=$ intrahepatic; $\mathrm{CMV}=$ cytomegalovirus infection; $\mathrm{E}-\mathrm{B}=$ Epstein-Barr virus infection; $\mathrm{BDN}=$ bile duct necrosis.

${ }^{a}$ Mean + S.E.M.

${ }^{b} \mathrm{p}<0.001$ vs. all groups.

${ }^{c}$ Considered as final secondary events, not the main cause of graft failure.

${ }^{d} \mathrm{p}<0.01$ vs. groups 2,3 and 4 .

'See text for specific causes.

obtained retrospectively after the failed allograft had been thoroughly examined pathologically were considered to be correct. Those not matching and poorly defined or nonspecific indications for re-OLTx were considered to be wrong.

The amount of RBCs, number of platelet packs, units of fresh frozen plasma and units of cryoprecipitate administered to each patient during the first OLTx procedure were obtained from the operative, anesthesia and blood bank records.

Statistical Analysis. All numerical data were expressed as mean values \pm S.E.M. Their conformity to a normal distribution was assessed by the Kolmogorov-Smirnov method. Multiple comparisons were made using ANOVA followed by the Scheffe test for group-to-group comparisons (for normal distributions) or by the nonparametric Kruskal-Wallis test followed by the Mann-Whitney $U$ test for variables that were not normally distributed. Student's $t$ test or the MannWhitney $U$ test were used for isolated comparisons between two groups. The $\chi^{2}$ test (with or without Yates' correction) was used for comparisons of qualitative variables. Actuarial survival of the patients was calculated by the life tables method.

\section{RESULTS}

Causes and Timing of Graft Failure. The 177 patients included in the analysis represented $19.6 \%$ of the total population receiving a first OLT $x$ at the University of Pittsburgh during the period encompassed by the study. The causes of graft failure, the respective mean graft survival time and the pathological findings present in the removed allografts are summarized in Table 2.

PNF accounted for $30 \%(n=53)$ of the failed grafts. In two cases, preexistent abnormalities in the donor liver (severe fatty change) may have been responsible for the failure of the graft to function, whereas in the remaining 51 cases a harvest-related injury was considered to be the principal factor responsible for the graft failure. In four cases, hyperacute humoral-mediated rejection was suspected as being present but was not proven.

IJ was the cause of graft failure in $9.6 \%(n=17)$ of the cases. A severe parenchymal necrosis, predominantly centrilobular, was found in all of these grafts.
$\mathrm{AR}$ was the cause of graft failure in $10.7 \%(\mathrm{n}=19$ ) of the cases. Two of these were thought to represent episodes of hyperacute, humoral-mediated rejection, whereas 17 were thought to be a result of cell-mediated rejection. In the two cases with hyperacute rejection, a linear deposition of immunoglobulin and complement along the hepatic vessels could be demonstrated immunohistochemically.

A VC accounted for $26.6 \%(n=47)$ of the failed grafts. Of these, 31 patients had HA thrombosis (HAT), 6 patients had PV thrombosis (PVT), 4 patients had HAT plus PVT, 1 patient had a suprahepatic inferior vena cava thrombosis and the remaining 5 patients had a nonthrombotic complication of the HA (stenosis in 2 cases and 1 case each of vascular-biliary fistula, mural degeneration and dissection of the donor HA). Among the 31 cases of HAT, 2 were a consequence of an attempt to repair an arterioportal fistula and an HA aneurysm. In one case, the HA was occluded as a result of focal fibrointimal hyperplasia. The findings present in these failed grafts included bile duct necrosis with a biliary leak in 12 patients, massive or submassive parenchymal necrosis in 32 patients and liver abscesses or microabscesses in 14 patients.

Twenty grafts (11.3\%) failed because of CR. The earliest such case was one of acute vanishing bile duct syndrome.

REC in the allograft was established in only eight cases. Seven were a result of recurrent type B virus infection and produced FHF of the liver graft (one patient), severe acute hepatitis (three patients), $\mathrm{CAH}$ (one patient) and cirrhosis (two patients). The remaining case was that of a recurrent HCC. Another four patients were included in this category although the diagnosis of REC could not be defined absolutely. Two of these four patients were transplanted for end-stage autoimmune hepatitis and the allograft developed a picture of $\mathrm{CAH}$ of the autoimmune type similar to that of the native liver. In addition, both of these livers also 


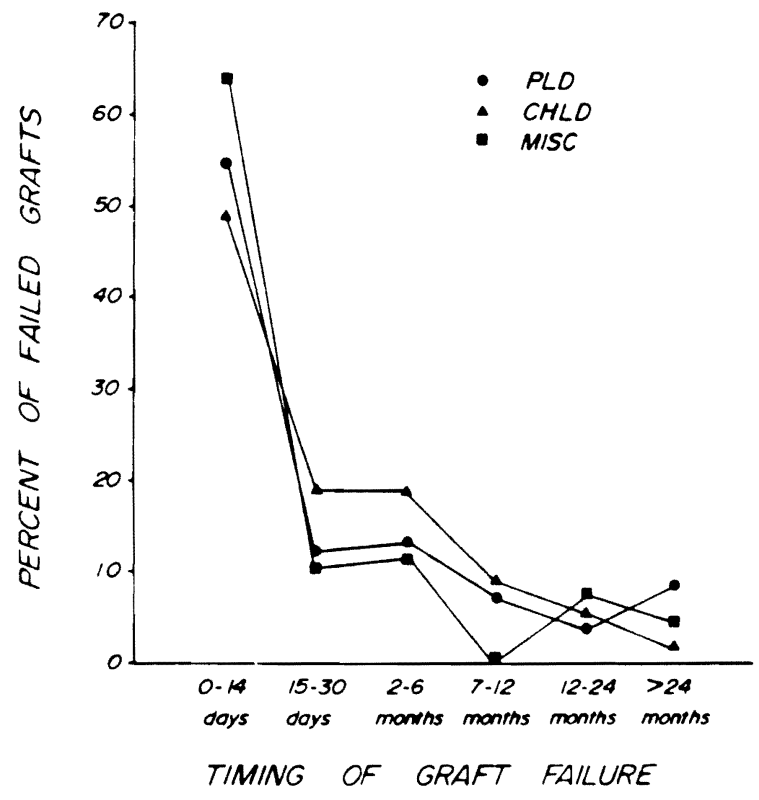

FIG. 2. Timing of graft failure according to primary liver disease among the 177 patients studied. MISC = patients with FHF, NLD and miscellaneous conditions (see text for specific disease included in each category)

showed findings consistent with moderate $A R$. One patient with FHF attributed to NANB virus infection had acute hepatitis in the allograft develop in which all other causes of graft failure could be eliminated. A second patient with $\mathrm{CAH}$ plus cirrhosis thought to be caused by NANB hepatitis had a similar histopathological picture in the allograft develop.

Finally, $5 \%(n=9)$ (MISC) of the cases did not fill any of the preceding identifiable categories. They included the following: nonrecurrent HBV (two cases), one of which was associated with severe CR; herpes hepatitis (one case); acute hepatitis of unidentified origin plus severe CR (one case); suppurative cholangitis (one case); severe acute cholangitis with associated ischemic damage (one case); bile duct necrosis with bile leak and associated cytomegalovirus hepatitis (one case); and two cases in which the cause of graft failure could not be established.

Timing of Graft Failure. Mean graft survival for all patients was $130.6 \pm 22.9$ days (range $=0$ to 2,073 ). The number of failed grafts decreased progressively with increasing time after OLTx, with $67.8 \%$ of all graft failures occurring in the first postoperative month and only $6.2 \%$ occurring $2 \mathrm{yr}$ or more after OLTx (Fig. 1). The mean graft survival of organs that failed because of PNF, IJ, AR and VC was significantly less ( $p<0.05$ or less) than that for grafts that failed because of CR or REC. In addition, among these four causes of early graft failure, PNF occurred significantly earlier than did any of the other three $(p<0.001)$ (Table 2$)$.

A highly significant association $(p<0.001$ ) was found between the cause and timing of graft failure when the population was distributed into the six time periods used
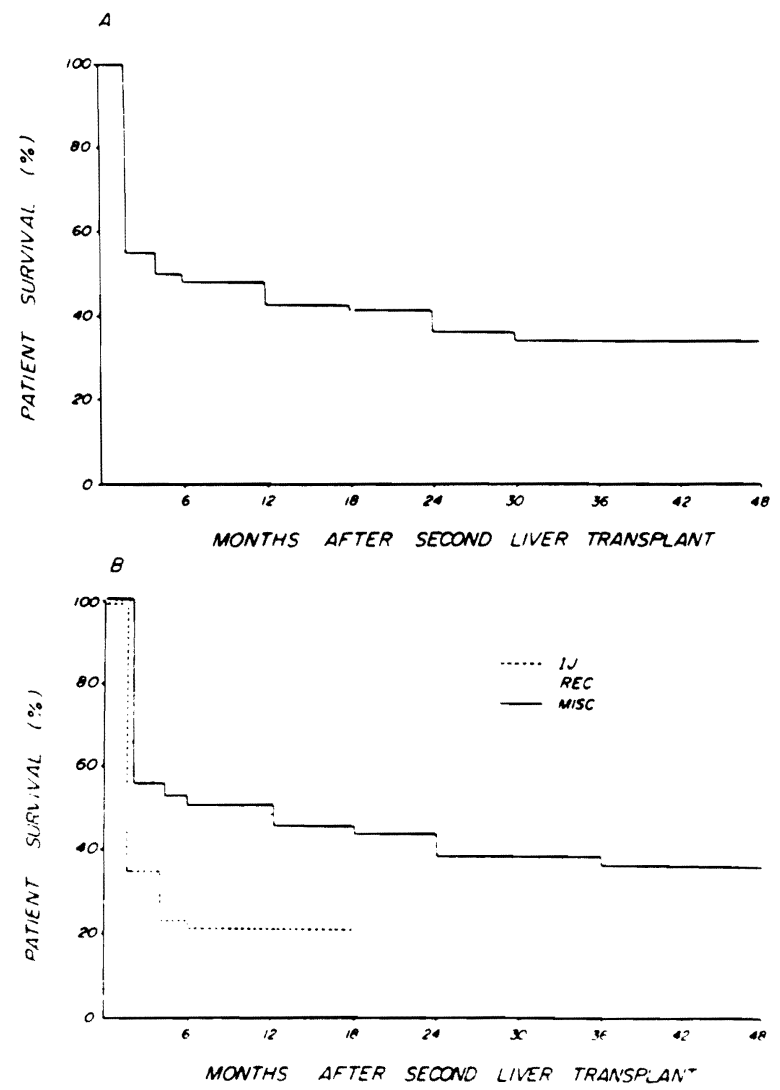

FIG. 3. (A) Actuarial survival after a second liver transplant for the 177 patients included in this study. (B) Influence of the cause of the initial graft failure on the survival of the patients after the second liver graft. For IJ, $\mathrm{n}=17$; for REC, $\mathrm{n}=12 . M I S C=$ patients with failed grafts because of PNF, AR, VC, CR and nonclassified causes (see text for specific conditions included in each group).

to classify the timing of graft failure (Table 3). Despite some minor overlap, the data in this table clearly demonstrate that early causes of graft failure are PNF, IJ, AR and VC, whereas late causes are CR and REC.

Characteristics of the Recipients Relative to the Cause and Timing of Graft Failure. The causes of graft failure were significantly different between patients who had transplants because of PLD and those who had transplants because of ChLD $(p<0.05)$ (Table 4). The principal differences between these two groups was the higher frequency of PNF and REC in the PLD group and the higher number of VC and CR in the ChLD group. In addition, it should be noted that $50 \%$ of patients with FHF had graft failure develop because of VC (HAT in all cases). Mean graft survival did not differ significantly among the various groups based on primary liver disease $(\mathrm{ChLD}=89.1 \pm 25.5$ days; $\mathrm{PLD}=166.2 \pm 41.2$ days; $\mathrm{NLD}=96.3 \pm 51.4$ days; and $\mathrm{FHF}=195.7 \pm 92.1$ days). The only exception was the very short graft survival found for patients within the MISC group $(4.5 \pm 1.1$ days $[p<0.01$ vs. ChLD, PLD and FHF]). Figure 2 graphically illustrates the parallel timing of graft failure in the three major primary liver disease groups. 
TABLE 3. Time distribution of the causes of graft failure in $\mathbf{1 7 7}$ cases studied

\begin{tabular}{|c|c|c|c|c|c|c|c|c|}
\hline \multirow[b]{2}{*}{ Cause of allograft failure } & \multirow[b]{2}{*}{ Number of cases } & \multicolumn{6}{|c|}{ Timing of graft failure (\%) } & \multirow[b]{2}{*}{ Total (\%) } \\
\hline & & $0-14$ days & 15-30 days & $2.6 \mathrm{mo}$ & 7-12 mo & 13-24 mo & More than 24 mo & \\
\hline PNF & 53 & 100 & - & - & - & - & - & 100 \\
\hline $\mathrm{AR}$ & 19 & 42.1 & 15.8 & 42.1 & - & - & - & 100 \\
\hline VC & 47 & 53.2 & 29.8 & 8.5 & 2.1 & 4.3 & 2.1 & 100 \\
\hline CR & 20 & - & - & 30 & 30 & 10 & 30 & 100 \\
\hline
\end{tabular}

$\chi^{2}$ value for the distribution $=174.28(\mathrm{p}<0.001)$.

TABLE 4. Relationship between cause of graft failure and primary liver disease in 177 cases studied

\begin{tabular}{|c|c|c|c|c|c|c|c|c|c|}
\hline $\begin{array}{c}\text { Primary liver } \\
\text { disease }\end{array}$ & $\begin{array}{c}\text { Number of } \\
\text { canes }\end{array}$ & PNF (\%) & $\mathrm{IJ}(\boldsymbol{\%})$ & AR (\%) & $\begin{array}{c}\text { Vascular } \\
\text { thrombosis (\%) }\end{array}$ & CR (\%) & REC (\%) & Mise (\%) & Total (\%) \\
\hline 1. $\mathrm{ChLD}^{b}$ & 54 & 18.5 & 11.1 & 11.1 & 37.0 & 16.7 & 0 & 5.6 & 100 \\
\hline 2. Chronic PLD & 85 & 35.3 & 8.2 & 13.0 & 20.0 & 9.4 & 11.8 & 2.3 & 100 \\
\hline 4. FHF & 14 & 14.3 & 0 & 7.1 & 50 & 7.1 & 7.1 & 14.3 & 100 \\
\hline 5. MISC & 8 & 75 & 12.5 & 0 & 12.5 & 0 & 0 & 0 & 100 \\
\hline
\end{tabular}

${ }^{a}$ See text for specific diseases included in each category.

${ }^{b} 1$ vs. $2: \chi^{2}$ value $=15.93(p<0.05)$.

The patient's gender did not significantly influence mean graft survival (men $=139.3 \pm 35.5$ days and women $=120.5 \pm 27.9$ ), nor did gender affect the cause of graft failure (PNF $=30.8 \%$ vs. $28.9 \%$, $\mathrm{IJ}=8.5 \%$ vs. $10.8 \%, \mathrm{AR}=12.7 \%$ vs. $8.4 \%, \mathrm{VC}=25.5 \%$ vs. $27.8 \%$, $\mathrm{CR}=8.5 \%$ vs. $14.4 \%$ and $\mathrm{MISC}=4.2 \%$ vs. $7.2 \%$ ), although REC was more frequent in men $(10.6 \%$ vs. $2.4 \%, 0.1>p>0.05$ ). This latter difference was the result of the fact that all cases of recurrent type $B$ virus infection occurred in men.

The mean age of the patients in the ischemic injury group $(49.8 \pm 2.2 \mathrm{yr})$ was significantly greater than it was for patients whose grafts failed because of PNF $(41.3 \pm 1.8 \mathrm{yr}, \mathrm{p}<0.01), \mathrm{AR}(35.5 \pm 2.7 \mathrm{yr}, \mathrm{p}<0.01)$ and $C R(36.0 \pm 2.7 \mathrm{yr}, \mathrm{p}<0.01)$. Of interest, the subgroup of patients with PVT was the oldest $(53.8 \pm 11.3$ yr) $(p<0.01)$ vs. all causes of graft failure). In addition to these differences between groups, patients with an immunological cause of graft failure were significantly $(p<0.01)$ younger $(35.8 \pm 1.9 \mathrm{yr})$ than those with graft ischemic injury $(44.0 \pm 2.0 \mathrm{yr})$ as a result of other causes $(43.4 \pm 1.5 \mathrm{yr})$. Patients whose grafts survived for more than $1 \mathrm{yr}(31.4 \pm 3.1 \mathrm{yr}$, $\mathrm{n}=20$ ) were significantly younger than those whose grafts did not survive a full year. The mean age of those whose grafts failed in the first postoperative month was $43.3 \pm 1.2 \mathrm{yr}(\mathrm{n}=120, \mathrm{p}<0.01)$, whereas those whose graft failed in the second through twelfth postoperative months was $40.4 \pm 2.1 \mathrm{yr}(\mathrm{n}=37, \mathrm{p}<0.01)$.

Intraoperative Consumption of Blood and Blood Products. The intraoperative requirement of RBCs $(25.1 \pm 2.8$ vs. $16.9 \pm 1.7$ units, $p<0.05)$, platelets $(19.6 \pm 1.8$ vs. $10.3 \pm 1.3$ units, $p<0.001)$, fresh frozen plasma $(18.3 \pm 2.2$ vs. $10.2 \pm 1.4$ units, $\mathrm{p}<0.01)$ and cryoprecipitate $(9.5 \pm 1.4$ vs. $5.2 \pm 1.2$ units, $p<0.05)$ was significantly greater in patients with PLD $(n=85)$ than for all other disease groups $(n=84)$, excluding those in the MISC category $(n=8)$. This latter group required the greatest amount of blood products.

Relevant to the issue of graft failure, the greatest requirement for blood products was by patients in the PNF and ischemic injury groups (Table 5). Thus a significantly greater requirement for blood and blood products was seen in patients with graft failure occurring in the first postoperative month (Table 6).

Preoperative Diagnosis of the Cause of Graft Failure. A preoperative diagnosis for graft failure was not specifically identified in the record of seven patients. In addition, if the patients in the ischemic injury group are excluded from the analysis because this diagnosis is not evident until the liver is removed, a total of 153 cases were available for analysis. The overall accuracy of the preoperative diagnosis for the cause of graft failure was $77.7 \%$. The greatest diagnostic accuracy rate was found for CR (100\%). Second was REC (91.6\%). The poorest rate was obtained for cases with VC (63.8\%), AR (66.6\%) and MISC (66.6\%). The diagnosis of PNF as a cause of graft failure occupied an intermediate value $(84.0 \%)$. Thus the preoperative diagnostic accuracy rate for causes of graft loss was significantly better for late failures $(92.4 \%$ accurate) than it was for early failing grafts $(70.0 \%$ accurate) $(p<0.01)$.

Patient Survival After the Second OLTx-6-Mo Survival. Overall 6-mo survival after a second OLTx was $46.3 \%$. With regard to the cause of first-graft failure, the greatest second-graft survival rate was achieved by patients in the CR group (65\%). The group with the poorest second-graft survival rate consisted of those patients with ischemic injury $(23 \%, \mathrm{p}<0.05)$ as the 
TABLE 5. Intraoperative requirement for blood and blood products at the time of first OLTx and subsequent cause of graft failure in 177 patients studied

\begin{tabular}{lcccc}
\hline $\begin{array}{c}\text { Cause of graft } \\
\text { failure }\end{array}$ & RBCs (units) & $\begin{array}{c}\text { Platelets } \\
\text { (units) }\end{array}$ & $\begin{array}{c}\text { Fresh frozen } \\
\text { plamma (units) }\end{array}$ & $\begin{array}{c}\text { Cryoprecipitate } \\
\text { (units) }\end{array}$ \\
\hline 1. PNF & $33.1 \pm 4.2^{a}$ & $20.5 \pm 2.5^{b}$ & $21.8 \pm 3.5^{c}$ & $12.6 \pm 2.0^{c}$ \\
2. IJ & $33.8 \pm 9.5^{d}$ & $14.2 \pm 4.7^{d}$ & $19.9 \pm 6.2$ & $6.8 \pm 4.1$ \\
3. AR & $16.3 \pm 3.5$ & $13.1 \pm 3.2$ & $12.8 \pm 3.0$ & $6.7 \pm 2.2$ \\
4. VC & $18.0 \pm 2.6$ & $13.5 \pm 1.8$ & $9.8 \pm 1.4$ & $4.8 \pm 1.1$ \\
5. CR & $7.8 \pm 1.0$ & $8.1 \pm 2.6$ & $6.4 \pm 1.0$ & $1.7 \pm 0.9$ \\
6. REC & $18.4 \pm 2.4$ & $18.1 \pm 3.7$ & $15.6 \pm 3.9$ & $6.8 \pm 2.4$ \\
7. MISC & $20.7 \pm 2.2$ & $13.0 \pm 3.8$ & $15.3 \pm 3.4$ & $9.6 \pm 4.8$ \\
\hline
\end{tabular}

Results are mean \pm S.E.M

${ }^{a} \mathrm{p}<0.01$ vs. 3,4 and 5 .

${ }^{b} p<0.05$ vs. 3 and 4 , and $p<0.01$ vs. 5 .

c $p<0.01$ vs. 4 and 5 .

${ }^{d} \mathrm{p}<0.01$ vs. 5 .

cause for the failure of their first graft. Patients in the remaining groups, classified on the basis of firstgraft failure, showed intermediate survival rates $(\mathrm{PNF}=49 \%, \mathrm{AR}=53 \%, \mathrm{VC}=49 \%, \mathrm{REC}=33 \%$, and MISC $=33 \%$ ). Second-graft 6 -mo survival was significantly greater for recipients younger than $40 \mathrm{yr}$ at the time of the initial OLTx than it was for those who were older than $40 \mathrm{yr}$ at the time of first grafting $(56.4 \%$ vs. $39.4 \%, \mathrm{p}<0.05$ ). Recipient gender (men $=44.7 \%$ and women $=50.6 \%$ ) did not affect second-graft survival rates.

No significant difference for second-graft 6-mo survival was evident for patients in the different disease groups used to classify the original liver disease ( $\mathrm{ChLD}=44 \%, \mathrm{PLD}=48 \%, \mathrm{FHF}=50 \%, \mathrm{NLD}=50 \%$ and MISC $=37 \%)$. Among patients with PLD, those with $\mathrm{HBV}=$ induced cirrhosis showed a significantly poorer 6-mo survival $(16.6 \%, \mathrm{n}=18)$ than did all remaining groups $(57.8 \%, \mathrm{n}=67, \mathrm{p}<0.01)$.

Patients who survived after the second liver graft for 6 mo or more were younger and had a significantly smaller first-OLTx requirement for blood and blood products (Table 7).

Actuarial Survival for Second Liver Grafts. The actuarial survival of the patients included in this study from the time of their second OLTx is illustrated in Figure 3A. Most of the deaths (45\%) after the second OLTx occurred in the first 2 mo after the second transplant procedure. The death rate was minimal after an initial $12 \mathrm{mo}$. The influence of the cause of first-graft failure on second-graft patient survival is shown in Figure 3B. The poor prognosis for patients with firstgraft failure caused by ischemic injury and disease recurrence is clearly demonstrated. All of the patients in the remaining categories for cause of first-graft failure can be viewed as a single group because their respective survivals after second grafting were similar.

\section{DISCUSSION}

This study has identified the principal causes and the timing of graft failure after initial OLTx in a population of patients who received a second OLTx. In most studies performed before this, the cause of graft failure has been
TABLE 6. Intraoperative requirement for blood and blood products at time of first OLTx and timing of subsequent graft failure in 177 patients studied

\begin{tabular}{lrcc}
\hline & \multicolumn{3}{c}{ Timing of graft failure } \\
\cline { 2 - 4 } Blood or blood product & \multicolumn{1}{c}{ Legs than } & $\begin{array}{c}\text { More than } \\
\text { 30 days }\end{array}$ & p value \\
\hline RBCs (units) & $27.6 \pm 2.6$ & $12.8 \pm 1.6$ & $<0.001$ \\
Platelets (units) & $16.9 \pm 1.5$ & $11.4 \pm 1.5$ & $<0.05$ \\
Fresh frozen plasma (units) & $17.4 \pm 2.0$ & $9.8 \pm 1.3$ & $<0.01$ \\
Cryprecipitate (units) & $8.9 \pm 1.2$ & $4.1 \pm 0.9$ & $<0.01$ \\
\hline
\end{tabular}

Values are mean \pm S.E.M.

classified into three or fewer groups, such as PNF, rejection and technical complications (5-7). This study extended such data and examined graft failure across six distinct categories. In addition, a characteristic timing for each type of graft failure was demonstrated. Thus despite some overlap in the period from 2 to 6 mo after initial OLTx, these results demonstrate that the main causes of early graft failure are PNF, ischemic injury, AR and VC, whereas those for late graft failure are CR and REC.

The first postoperative month constitutes the period of greatest risk for graft failure after OLTx. A total of $67 \%$ of the grafts fail in this first month. During this same period, PNF is the single most frequent cause of graft failure and accounts for $42 \%$ of the early cases of graft loss and for $30 \%$ of the total graft losses independent of time.

The specific mechanisms responsible for PNF remain to be determined but clearly include prolonged warm and cold ischemia times, preservation and reperfusion injuries and other less well-identified injuries. In only two cases were specific abnormalities of the donor identified as possible causes for subsequent graft failure. In the remaining cases, a putative harvest injury (prolonged warm or cold ischemia or reperfusion injury) was the most frequent probable underlying factor. However, it is also quite likely that other factors may have contributed to the graft injury that ultimately resulted in the phenomenon collectively identified as 
TABLE 7. Influence of factors related to first OLTx on 6-mo patient survival after second OLTx

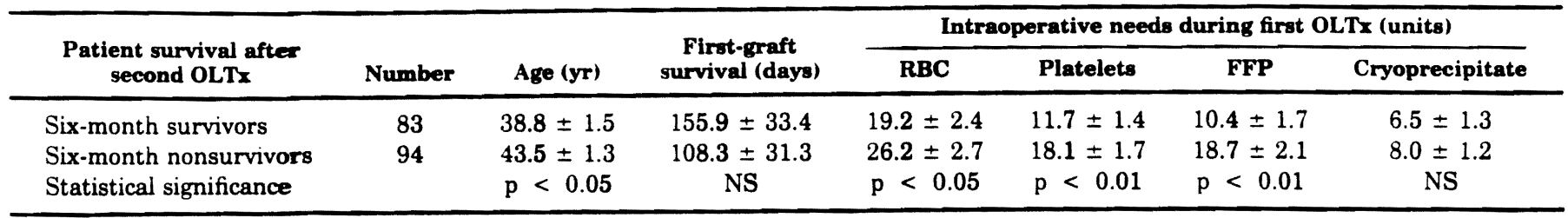

Results are mean \pm S.E.M.

$\mathrm{FFP}=$ fresh frozen plasma.

PNF. Hemodynamic instability is a frequent problem in patients with PNF, as judged by their requirements for blood and blood products during the OLTx procedure. Whether this initiates a primary malfunction of the donor organ, occurs as a result of intraoperative complications derived from technical factors, is a particular characteristic of the recipient at risk for PNF or is even a combination of these factors remains to be determined. The greater frequency of PNF in patients with PLD than in those with ChLD suggests that recipient factors may contribute. at least in part, to the development of PNF. Until accurate methods are available to determine the degree of graft function immediately before and after implantation, the role of recipient factors in the pathogenesis of PNF will remain uncertain. Although hyperacute humoral-mediated rejection is considered to be a relatively infrequent event in OLTx (14), the possibility cannot be excluded that many, if not most, of the cases of PNF are mediated. at least in part, by immunological events. In this series, only two cases of probable hyperacute rejection could be identified. Because the characteristic vascular deposition of complement and immunoglobulins is transient in cases of hyperacute rejection (14), cases can either be missed altogether or masked, and as a result they are entered inappropriately into the generic category of PNF. It is also important to note that either hyperacute rejection or reperfusion injury can initiate a severe coagulopathy that leads to bleeding, hypoperfusion and a requirement for more blood and blood products, each of which can either initiate or contribute further to the other existing factor or factors that lead to PNF. The identification of these additional factors possibly responsible for PNF and whether they are of donor, harvest or recipient origin should allow either for their amelioration or elimination and, as a result, lead to a substantial improvement in OLTx results.

This study revealed a heretofore unrecognized category of graft failure found in the early post-OLTx period. Specifically, 17 patients were found to have graft necrosis in the absence of any identifiable vascular complication (IJ). Among these cases, a partial or total recovery of initial graft dysfunction was evident followed later by graft loss sometime after the first postoperative week. Thus this group of graft failures is clearly different from those in which PNF is evident immediately. The intraoperative requirement for blood and blood products in this latter group of patients was equal to or greater than that seen in those with PNF.
Moreover, the mean age of the patients in this new category was greater than in any other category and suggests that poor recipient condition may have been an underlying factor for the graft failure in this group. It is important to emphasize that no case of ischemic injury wsa found in patients younger than $30 \mathrm{yr}$ and then only in two patients younger than $40 \mathrm{yr}$. Although ischemic injury represented only $9.6 \%$ of the total cases of graft failure, its importance derives from the very poor outcome of this subgroup of patients after the second OLTx. It is likely that the underlying systemic factors leading to an initial graft failure in this group also contribute substantially to the poor outcome of these patients after their second OLTx.

Rejection accounted for 39 graft losses, half of which were AR and half of which were CR. Rejection, therefore, accounts for $22 \%$ of the total graft failures after OLTx. Thus despite the fact that AR occurs in about $70 \%$ to $80 \%$ of all OLTx recipients (1-3), uncontrollable rejection that leads to graft failure is quite unusual. Nonetheless, these same data also highlight the need for better immunosuppressive reagents and regimens to control severe episodes of graft rejection. In this context, the recent results obtained in a small series of patients with the new immunosuppressant, FK 506, are extremely encouraging (15). Because this drug appears to be useful in the management of both $A R$ and CR, the need for repeat transplants for rejection ought to be reduced in the future as this drug becomes more widely available.

VCs were the second leading cause of graft failure after OLTx. This observation is in agreement with the relatively high frequency of vascular problems demonstrated in previous studies of OLTx recipients $(5-7,16)$. These complications were predominantly early events, with all but five cases occurring within the first 3 mo after the operation. Among the various types of VC, HAT was the most frequent. Initially considered to be a technical event, recent reports suggest that other factors may also predispose the recipient to experience this particular complication. High hematocrit values, low HA blood flow rates, infection, rejection and other factors, $(13,17,18)$ are believed to represent nontechnical risk factors for the development of HAT, although some of these factors might not be relevant to adult patients (19). These issues have not been addressed in this study.

Moderate or severe AR was documented in 8 of 26 grafts removed because of HAT within the first 3 mo after the operation, suggesting that the coupling rate of 
such conditions might be greater than that expected on a random basis. Additional studies to search for such an association are thus warranted. PVT was an infrequent complication in this series $(5-7,16)$.

These results reemphasize the previously reported high rate of recurrence of $\mathrm{HBV}$ infection in the liver allograft (20). Because no effective method is yet available to prevent this complication, it remains a major problem for patients who have transplants for this indication $(1,3)$. Despite an almost universal diseaserecurrence rate in patients who have transplants for this indication, the mean first-graft survival in these particular patients was $\mathbf{5 5 0}$ days, a time period sufficiently long to make HBV infection a relative rather than an absolute contraindication for OLTx. The low recurrence rate of neoplasia in this series should be considered cautiously because most patients with neoplastic disease whose grafts failed had them do so in the early postoperative period as a result of a variety of causes other than recurrent disease. Recurrence of the original hepatic malignancy within a graft requires initial survival and is a frequent cause of late death or graft failure $(21,22)$. Whether disease recurrence occurs in cases of NANB or autoimmune hepatitis remains to be determined. In contrast to recent reports (22) claiming recurrence of PBC in liver allografts, such a condition could not be identified in this large series consisting of 33 patients with $\mathrm{PBC}$ as the indication for their transplant.

Biliary tract complications were one of the more prominent sources of morbidity and mortality in the initial years of OLTx (9); technical improvements have led to a reduction of such problems in the last several years $(9,23)$. Severe biliary tract complications found in removed grafts were thought almost universally to be secondary to HAT because the blood supply for the extrahepatic bile ducts in these cases is dependent solely on HA flow. Thus it is essential to specifically evaluate the HA in all patients with suspected or recognized biliary tract complications.

With regard to the preoperative diagnosis of the cause for first-graft failure, the marked difference observed in the diagnostic accuracy rate for early and late graft failures highlights the complexity of the early postoperative period. The many different causes capable of leading to graft failure during this period and the multitude of complications that can occur in the immediate postoperative period $(1-4,11)$ probably determine the difficulty in establishing an accurate preoperative diagnosis in such cases. In contrast, the almost $100 \%$ diagnostic accuracy rate observed after the first post-OLTx month indicates that in most patients identifying a specific cause for graft failure beyond the first postoperative month is not a clinical problem.

The overall patient survival rates of $55 \%$ at $2 \mathrm{mo}$ and $46 \%$ at 6 mo after a second OLTx and the actuarial survival of $43 \%$ at $1 \mathrm{yr}$ and $35 \%$ at $4 \mathrm{yr}$ clearly document that the initial 6-mo postoperative period and specifically the first 2 mo after retransplantation constitute the period of highest risk for mortality for patients under- going a second OLTx. However, it should be emphasized that the late mortality is very small, rendering the prognosis for patients surviving beyond this initial critical period quite good. Second-transplant patient survival rates herein reported are higher than those found in a study that included patients from four centers (8), but they are comparable with those obtained from this institution some years ago (5) and other centers (6), despite the small number of cases included in both of these earlier series $(5,6)$. Although quantitatively different, the high mortality seen in the early postoperative period after second OLTx closely mimics the evolution of patients subjected to a single OLTx procedure $(1,3)$. The poorer prognosis for retransplanted patients may be related to the setting in which retransplantation must be performed (5). Excluding the above mentioned cases of patients who had retransplants because of ischemic injury and disease recurrence and whose prognosis was poor, the precise reason for retransplantation seems to have little or no effect on subsequent patient survival. Thus retransplantation because of PNF might not be associated with a poor prognosis as has been reported previously (5). In addition, other factors likely to influence early patient survival after liver retransplantation have been identified as a result of this study. Advanced age and an excessive requirement for blood and blood products at the time of the first OLTx appears to represent a risk factor for early death after a second OLTx. Whether a significant association exists between these factors and a specific cause of death after retransplantation has not been addressed as part of this study.

In summary, this study establishes a pattern of causes and timing of first allograft failure based on the results observed in a large population of patients undergoing liver retransplantation. In addition, it confirms the effectiveness of the use of liver retransplantation as a life-saving maneuver for patients whose first allograft fails.

\section{REFERENCES}

1. Maddrey WC, Van Thiel DH. Liver transplantation: an overview. HEPATOLOGY 1988;8:948-959.

2. Starzl TE, Demetris AJ, Van Thiel DH. Liver transplantation / first of two parts|. N Engl J Med 1989;321:1014-1022.

3. Starzl TE, Demetris AJ, Van Thiel DH. Liver transplantation [second of two parts|. N Engl J Med 1989;321:1092-1099.

4. Carithers RL, Fairman RP, Mendez-Picon G, Posner MP, Mills AS, Friedenberg KT. Postoperative care. In: Maddrey WC, ed. Transplantation of the liver. New York: Elsevier. 1988:111-141.

5. Shaw BW, Gordon RD. Iwatsuki S. Starzl TE. Hepatic retransplantation. Transplant Proc 1985:17:264-271.

6. Busuttil RW, Colonna JO. Hiatt JR. The first 100 liver transplants at UCLA. Ann Surg 1987;206:387-402.

7. Krom RA. Wiesner RH, Rettke SR. The first 100 liver transplants at the Mayo Clinic. Mayo Clin Proc 1989:64:84-94.

8. Scharschmidt BF. Human liver transplantation: analysis of data on 540 patients from four centers. HEPATOLOGY 1984:4(suppl): 95S-101S.

9. Starzl TE, Iwatsuki S, Van Thiel DH, Gartner JC, Zitelli BJ, Malatack JJ, Schade RR, et al. Evolution of liver transplantation. HEPATOLOGY 1982;2:614-636.

10. Van Thiel DH. Schade RR. Starzl TE. Iwatsuki S, Shaw BW. 
Gavaler JS, Dugas M. Liver transplantation in adults. HEPATOLOGY 1982;2:637-640.

11. Kusne S, Dummer JS, Singh N, Iwatsuki S, Makowka L, Esquivel $\mathrm{C}$, Tzakis $\mathrm{A}$, et al. Infections after liver transplantation: an analysis of 101 consecutive cases. Medicine 1988;67:132-143.

12. Demetris AJ, Lasky S, Van Thiel DH, Starzl TE, Dekker A. Pathology of hepatic transplantation: a review of 62 adult allograft recipients immunosuppressed with a cyclosporine/steroid regimen. Am J Pathol 1985;118:151-161.

13. Tzakis AG, Gordon RD, Shaw BW Jr, Iwatsuki S, Starzl TE. Clinical presentation of hepatic artery thrombosis after liver transplantation in the cyclosporine era. Transplantation 1985;40: 667-671.

14. Starzl TE, Demetris AJ, Todo S, Kang Y, Tzakis A, Duquesnoy R, Makowka L, et al. Evidence for hyperacute rejection of human liver grafts: the case of the canary kidneys. Clin Transplantation 1989;3:37-45.

15. Starzl TE, Todo S, Fung J, Demetris AJ, Venkataramanan R, Jain A. FK 506 for liver, kidney, and pancrease transplantation. Lancet 1989;2:1000-1004

16. Wozney P, Zajko AB. Bron KM, Point S, Starzl TE. Vascular complications after liver transplantation: a 5-year experience. AJR Am J Roentgenol 1986;147:657-663.

17. Yanaga K, Makowka L, Starzl TE. Is hepatic artery thrombosis after liver transplantation really a surgical complication? Transplant Proc 1989;21:3511-3513.

18. Yanaga K, Makowka L, Shimada M, Esquivel CO, Bowman JS, Todo S, Tzakis AG, et al. Hepatic artery thrombosis after pediatric liver transplantation: assessment of blood flow measurement in allografts. Clin Transplantation 1989;3:184-189.

19. Klintmalm GB, Olson LM, Pallsen AW, Whitten CW, Husberg BS. Hepatic artery thrombosis after liver transplantation: intraoperative electromagnetic blood flow evaluation. Transplant Proc $1988 ; 20: 616-619$.

20. Demetris AJ, Jaffe R, Sheahan DG, Burnham J, Spero J, Iwatsuki S, Van Thiel DH, et al. Recurrent hepatitis B in liver allograft recipients: differentiation between viral hepatitis $B$ and rejection. Am J Pathol 1986;125:161-172.

21. Ringe B, Wittekind C, Bechstein WO, Bunzendahl H, Pichlmayr R. The role of liver transplantation in hepatobiliary malignancy: a retrospective analysis of 95 patients with particular regard to tumor stage and recurrence. Ann Surg 1989;209:88-98.

22. Polson RJ, Protmann B, Neuberger J, Calne RY, Williams R. Evidence for disease recurrence after liver transplantation for primary biliary cirrhosis. Gastroenterology 1989:97:715-725.

23. Lerut J, Gordon RD, Iwatsuki SI, Esquivel CO, Todo S, Tzakis AG, Starzl TE. Biliary tract complications in human orthotopic liver transplantation. Transplantation 1987;43:47-51. 